\title{
A Systematic Review and Meta-analysis of Randomized Placebo-controlled Trials 1 Year after Starting Sodium-glucose Transporter-2 Inhibitors in Heart Failure Patients with Reduced Ventricular Ejection Fraction
}

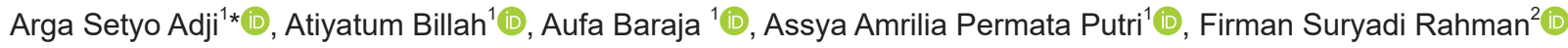 \\ ${ }^{1}$ Faculty of Medicine, Universitas Hang Tuah Surabaya, Surabaya, East Java, Indonesia; ${ }^{2}$ Department of Public Health, Faculty \\ of Public Health, Universitas Airlangga, Surabaya, East Java, Indonesia
}

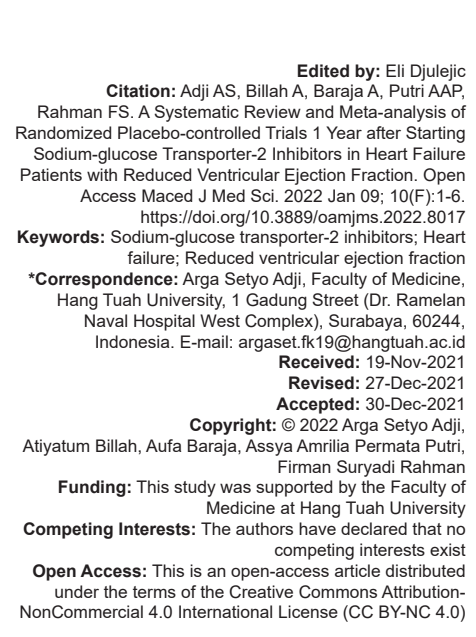

\section{Introduction}

Sodium-glucose transport-2 (SGLT-2 inhibitor) in type 2 diabetes mellitus has shown huge decrease in hospitalization of cardiovascular breakdown [1], [2], [3]. Recently, there have been clinical preliminaries to assess SGLT-2 inhibitor in cardiovascular breakdown with diminished launch part. There are two clinical preliminaries that can give sufficient information to perform further examination, Dapagliflozin and Prevention of Adverse Outcomes in Heart Failure [DAPA-HF] and EMPEROR-Reduced preliminary [4], [5].

DAPA-HF trial is a study to assess the impact of dapagliflozin in ongoing cardiovascular breakdown with diminished launch division with EMPEROR-Reduced is a study to evaluate effect of empaglifozins [4], [5]. Both articles showed significant reduction in both composite and individual outcome. Composite outcome is composite of cardiovascular mortality and hospitalization of HF, meanwhile, individual outcomes are all-cause mortality, cardiovascular mortality, and hospitalization of HF.

DAPA-HF and EMPEROR-Reduced are the main preliminaries to indicate the task of SGLT-2 inhibitor in suggestive cardiovascular breakdown with diminished launch division HF with reduced ejection fraction (HFrEF). Unfortunatenly, both clinical trials did not show any data about natriuretic peptide and echocardiography. Utilizing information from DAPA-HF and EMPEROR-Reduced, we performed metaexamination to appraise impact of SGLT-2 inhibitor with dapaglifozins and empaglifozin in composite of cardiovascular mortality and hospitalization of cardiovascular breakdown, all-cause mortality, cardiovascular mortality, and hospitalization of cardiovascular breakdown [4], [5]. 


\section{Methods}

\section{Data search}

We performed deliberate audit and metainvestigation utilizing proposals from Cochrane also the Preferred Reporting Item for Systematic Reviews and Meta-assessment (PRISMA) rules. We performed deliberate literature search from various electronic databases. Data search was performed from August 1, 2021 to August 19, 2021. We included free-cost electronic databases such as PubMed, ResearchGate, Cochrane, Clinicaltrial.gov, and Science Direct. We used keywords "SGLT-2 Inhibitor" and "HF" in order to search literature in electronic databases.

\section{Selection criteria}

We included determination models that met our choice measures: (1) randomized controlled trials preliminaries (RCTs), (2) placebo-controlled trial performed as comparison, (3) 1-year clinical and cardiovascular outcome, (4) all the patients have left ventricular ejection fraction (LVEF) $<40 \%$, (5) patient with or without diabetes, (6) announcing clinical and cardiovascular results, for example, composite of cardiovascular mortality with hospitalization of cardiovascular breakdown, all-cause mortality, cardiovascular mortality and hospitalization of cardiovascular breakdown. Exclusion criteria for our research are (1) non RCT, (for example casecontrol, review associate, imminent partner, clear review, etc.) (2) overlapping patient population, (3) placebocontrolled trial is not performed, (4) with cross-over design, (5) clinical and cardiovascular outcome is not measured within 1-year therapy, (6) study included cardiovascular breakdown with saved discharge portion LVEF $>50 \%$.

\section{Outcome definition}

There are four major cardiovascular outcomes mentioned in our research composite of cardiovascular mortality with hospitalization of cardiovascular breakdown, all-cause mortality, cardiovascular mortality, and hospitalization of cardiovascular breakdown. Both trials have the same definition of cardiovascular outcome.

All-cause mortality is described as noncardiovascular death and is defined as passing because of pneumonic distress; demise because of renal distress; demise because of gastrointestinal reason; demise due to hepatobiliary illness; demise because of disease (including sepsis); demise due to inflammatory (for example: Systemic Inflammatory Response Syndrome/Immune (including autoimmune)); hemorrhages from either cardiovascular bleeding or stroke; death from non-cardiovascular method or medical procedure; passing because of injury, demise due to self-destruction; passing because of medication glut; passing because of neurological reason; and passing because of danger and other.

Cardiovascular mortality is portrayed as follows: passing because of myocardial localized necrosis; abrupt cardiovascular demise and passing because of cardiovascular breakdown and cardiogenic shock; passing because of stroke, demise due to cardiovascular strategy; passing due to cardiovascular hemorrhage; and passing because of other cardiovascular reason (for example aspiratory embolism or fringe course illness).

Hospitalization of HF is described as follows: patient is admitted with primary diagnosis of HF; length of stay in hospital for at least $24 \mathrm{~h}$; recorded new or deteriorating side effects of cardiovascular breakdown somewhere around one (dyspnea, decline exercise resilience, weariness, different manifestations of end-organ perfusion or volume over-burden); achieved something such as two actual assessment discoveries, including: peripheral edema, abdominal distension, S3 gallops, rapid weight gain related to fluid retention, documented at least laboratory criteria, such as increased level of B-type natriuretic peptide (BNP)/N-terminal great for BNP (NT-proBNP) (like BNP $>500 \mathrm{pg} / \mathrm{ml}$ or NT-proBNP $>2.000 \mathrm{pg} / \mathrm{ml}$ ); radiological evidence of aspiratory blockage; non-intrusive symptomatic clinically critical raised degree of left or right-sided ventricular filling pressure and obtrusive indicative proof with right heart catheterization showing pneumonic slim wedge pressure I >18 $\mathrm{mmHg}$; and focal venous tension $>12 \mathrm{mmHg}$ or cardiovascular record $<2.2 \mathrm{~L} / \mathrm{min} / \mathrm{m}$. Composite of cardiovascular mortality and hospitalization of cardiovascular breakdown is defined as composite of patient which has both events (cardiovascular mortality and hospitalization of HF) as previously described.

\section{Data analysis}

Two authors (A.B., A.S.) independently extracted data from electronic databases. Disagreements were resolved by consensus of three authors (A.B., A.A.). Treatment effect for binary endpoint was using relative risk (RR) with 95\% confidence intervals. Heterogeneity was assessed with Cochran $Q$ test and 12 estimation, with $\mathrm{I} 2>25 \%$ were considered tremendous for homogeneity. We used a fixed-sway model for endpoints with $12<25 \%$ (low heterogeneity/homogeneity). For results with high heterogeneity, DerSimonian and Laird subjective effect model were used. Mantel-Haenszel statistic was used in comparing between groups due to dichotomous data type. We performed statistical analysis using software Revman 5.5. (Nordic Cochrane focus, The Cochrane Collaboration, Copenhagen, Denmark). 


\section{Results}

The characteristic of both DAPA-HF and EMPEROR-Reduced trial is RCT, LVEF $<40 \%$, with or without diabetes, placebo-controlled trial as comparison.

\section{Search result}

Database search was performed from August 1, 2021 to August 19, 2021 and found 954 articles in five databases (PubMed [ $n=54]$, Cochrane [ $n=61$ ], Science Direct [ $n=659$ ], ResearchGate [ $n=100]$, Clinicaltrial. gov [ $n=80])$. We removed duplicate articles $(n=53)$. We also removed articles with no full-text $(n=99)$. All full text articles were further analyzed $(n=802)$. We excluded full text articles for: non-relevance $(n=357)$, book chapter ( $n=23)$, guideline $(n=19)$, study protocol $(n=3)$, editorial ( $n=60$ ), observational study including casecontrol, prospective cohort, retrospective cohort $(n=44)$ case report and case series $(n=14)$. There are only two articles included in our research. Systematic literature search is compiled in a PRISMA diagram in Figure 1.

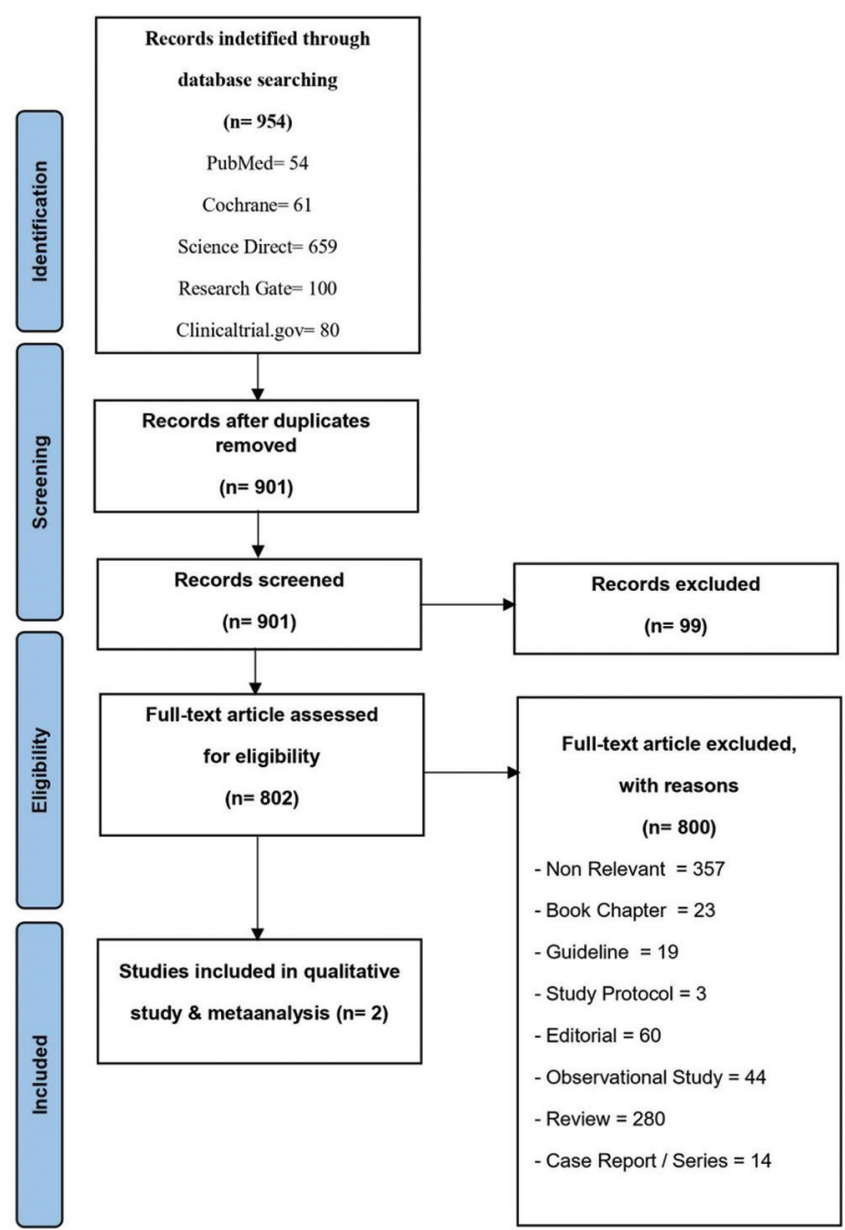

Figure 1: Preferred Reporting Item for Systematic Reviews and Metaassessment flow chart

\section{Outcome result}

We pooled about 8474 patients in two trials. Primary outcome is composite of cardiovascular demise and hospitalization of cardiovascular breakdown. In the interim, our optional result is all-cause mortality, cardiovascular mortality and hospitalization of cardiovascular breakdown. Our exploration showed huge decrease in all results contrasted and fake treatment within 1-year drug therapy. As shown in Figure 2 , our primary outcome is composite of cardiovascular mortality with hospitalization of HF which showed significant reduction $(R R=0.78$ [0.71-0.84], $p<$ $\left.0.00001, I^{2}=0 \%\right)$. Our secondary outcome is all-cause mortality which showed significant reduction $(\mathrm{RR}=0.88$ [0.79-0.98], $\left.p<0.03, I^{2}=1 \%\right)$, cardiovascular mortality showed significant reduction $(R R=0.87$ [0.77-0.99], $p$ $\left.<0.03, \mathrm{I}^{2}=1 \%\right)$ and hospitalization of $\mathrm{HF}(\mathrm{RR}=0.72$ [0.65-0.81], $p<0.00001, \mathrm{I}^{2}=0 \%$ ).

\section{Discussion}

The DAPA-HF and EMPEROR-Reduced preliminaries included patients with and without diabetes who had already been diagnosed with HFrEF and were receiving appropriate $\mathrm{HF}$ treatment as a result of those findings being expanded to include these patients [4], [5]. There was overlap and complementarity in the patient populations in the two trials, representing the wide range of HFrEF patients encountered in clinical practice. This meta-analysis shows how empagliflozin and dapagliflozin in individuals with HFrEF have the same cardiovascular benefits in both trials [4], [5].

Mechanism of SGLT-2 inhibitor in HF remains unclear. Hypertension is a preventable risk factor of HF. SGLT-2 inhibitor showed reduction of blood pressure and some beneficial effect of SGLT-2 inhibitor identified with this pulse worked on heart vivacious with SGLT-2 inhibitor bringing down impact [6]. Though the exact mechanism of SGLT-2 inhibition lowering effect remains unclear, they are presumably intervened by osmotic and diuretic effect of SGLT-2 inhibitor. SGLT- 2 inhibitor can result in 30\% - 60\% increase in urinary sodium excretion [7]. Antihypertensive effect of SGLT- 2 inhibitor is more prominent than thiazide diuretic when used in combination with b-blocker or calcium antagonist [8]. For low blood pressure effect, SGLT-2 inhibitor may also promote natriuresis and may bring down heart afterload, with resultant improvement in cardiovascular viability and ventricular vein coupling and glucosuria. EMPA-REG OUTCOME trial showed increase of hematocrit value in empaglifozins group both in empaglifozin $10 \mathrm{mg}(4.8 \pm 5.5 \%)$ and empaglifozins $25 \mathrm{mg}(5.0 \pm 5.3 \%)$ compared with placebo group 


\begin{tabular}{|c|c|c|c|c|c|c|c|c|c|c|}
\hline \multirow[b]{2}{*}{ Study or Subgroup } & \multicolumn{2}{|c|}{ SGLT-2 Inhibitor } & \multicolumn{2}{|c|}{ Placebo } & \multirow[b]{2}{*}{ Weight } & \multicolumn{2}{|l|}{ Risk Ratio } & \multirow{2}{*}{\multicolumn{3}{|c|}{$\begin{array}{c}\text { Risk Ratio } \\
\text { M-H, Fixed, } 95 \% \mathrm{Cl}\end{array}$}} \\
\hline & Events & Total & Events & Total & & M-H, Fixed, $95 \% \mathrm{Cl}$ & Year & & & \\
\hline DAPA-HF & 386 & 2373 & 502 & 2371 & $52.1 \%$ & $0.77[0.68,0.87]$ & 2019 & $\mathbf{\square}$ & & \\
\hline EMPEROR-Reduced & 361 & 1863 & 462 & 1867 & $47.9 \%$ & $0.78[0.69,0.88]$ & 2020 & $\mathbf{\square}$ & & \\
\hline Total $(95 \% \mathrm{Cl})$ & & 4236 & & 4238 & $100.0 \%$ & $0.78[0.71,0.84]$ & & $\downarrow$ & & \\
\hline Total events & 747 & & 964 & & & & & & & \\
\hline \multicolumn{5}{|c|}{$\begin{array}{l}\text { Heterogeneity: } C h i^{2}=0.05, \mathrm{df}=1(P=0.83) ; i^{2}=0 \% \\
\text { Test for overall effect: } Z=5.84(P<0.00001)\end{array}$} & & & & $\begin{array}{lll}0.01 & 0.1 & 1 \\
\text { Favours SGLT-2 Inhibitor } & \\
F\end{array}$ & $\begin{array}{c}10 \\
\text { Favours control }\end{array}$ & 100 \\
\hline a & \multicolumn{2}{|c|}{ SGLT-2 Inhibitor } & \multicolumn{2}{|c|}{ Placebo } & \multicolumn{3}{|c|}{ Risk Ratio } & \multirow{2}{*}{\multicolumn{3}{|c|}{$\begin{array}{c}\text { Risk Ratio } \\
\text { M-H, Fixed, } 95 \% \mathrm{Cl} \\
\end{array}$}} \\
\hline Study or Subgroup & Events & Total & Events & Total & Weight & M-H, Fixed, $95 \% \mathrm{Cl}$ & Year & & & \\
\hline DAPA-HF & 276 & 2373 & 329 & 2371 & $55.3 \%$ & $0.84[0.72,0.97]$ & 2019 & $\square$ & & \\
\hline EMPEROR-Reduced & 249 & 1863 & 266 & 1867 & $44.7 \%$ & $0.94[0.80,1.10]$ & 2020 & 단 & & \\
\hline Total $(95 \% \mathrm{Cl})$ & & 4236 & & 4238 & $100.0 \%$ & $0.88[0.79,0.98]$ & & 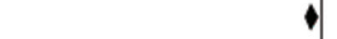 & & \\
\hline Total events & 525 & & 595 & & & & & & & \\
\hline \multicolumn{5}{|c|}{$\begin{array}{l}\text { Heterogeneity: } \mathrm{Chi}^{2}=1.01, \mathrm{df}=1(\mathrm{P}=0.31) ; \mathrm{I}^{2}=1 \% \\
\text { Test for overall effect: } Z=2.23(P=0.03)\end{array}$} & & & & $\begin{array}{lll}0.01 & 0.1 & 1 \\
\text { Favours SGLT-2 Inhibitor }\end{array}$ & $\begin{array}{c}10 \\
\text { Favours Placebo }\end{array}$ & 100 \\
\hline b & \multicolumn{2}{|c|}{ SGLT-2 Inhibitor } & \multicolumn{2}{|c|}{ Placebo } & \multicolumn{3}{|c|}{ Risk Ratio } & \multirow{2}{*}{\multicolumn{3}{|c|}{$\begin{array}{l}\text { Risk Ratio } \\
\text { M-H, Fixed, } 95 \% \mathrm{Cl}\end{array}$}} \\
\hline Study or Subgroup & Events & Total & Events & Total & Weight & M-H, Fixed, $95 \% \mathrm{Cl}$ & Year & & & \\
\hline DAPA-HF & 227 & 2373 & 273 & 2371 & $57.5 \%$ & $0.83[0.70,0.98]$ & 2019 & 미 & & \\
\hline EMPEROR-Reduced & 187 & 1863 & 202 & 1867 & $42.5 \%$ & $0.93[0.77,1.12]$ & 2020 & 닥 & & \\
\hline Total $(95 \% \mathrm{Cl})$ & & 4236 & & 4238 & $100.0 \%$ & $0.87[0.77,0.99]$ & & $\Delta$ & & \\
\hline Total events & 414 & & 475 & & & & & & & \\
\hline $\begin{array}{l}\text { Heterogeneity: } \mathrm{Chi}^{2}=0 \\
\text { Test for overall effect: } Z\end{array}$ & $\begin{array}{l}74, \mathrm{df}=1(\mathrm{P} \\
=2.15(\mathrm{P}=\end{array}$ & $\begin{array}{l}=0.39) ; \\
\text { 03) }\end{array}$ & $F^{2}=0 \%$ & & & & & $\begin{array}{l}0.01 \\
\text { Favours SGLT-2 Inhibitor }\end{array}$ & $\begin{array}{c}10 \\
\text { Favours Placebo }\end{array}$ & 100 \\
\hline c & SGLI-2 In & brtor & Hacet & & & KIsk Katıo & & KIsk K & Katıo & \\
\hline Study or Subgroup & Events & Total & Events & Total & Weight & M-H, Fixed, $95 \% \mathrm{Cl}$ & Year & M-H, Fixed & $\mathrm{d}, 95 \% \mathrm{Cl}$ & \\
\hline DAPA-HF & 231 & 2373 & 318 & 2371 & $48.2 \%$ & $0.73[0.62,0.85]$ & 2019 & 믈 & & \\
\hline EMPEROR-Reduced & 246 & 1863 & 342 & 1867 & $51.8 \%$ & $0.72[0.62,0.84]$ & 2020 & $\mathbf{\square}$ & & \\
\hline Total $(95 \%$ Cl) & & 4236 & & 4238 & $100.0 \%$ & $0.72[0.65,0.81]$ & & $\downarrow$ & & \\
\hline Total events & 477 & & 660 & & & & & & & \\
\hline 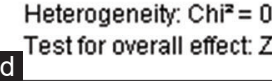 & $\begin{array}{l}00, \mathrm{df}=1(\mathrm{f} \\
=5.79(\mathrm{P}\end{array}$ & $=0.95)$ & $i^{2}=0 \%$ & & & & & $\begin{array}{l}0.01 \\
\text { Favours SGLT-2 Inhibitor }\end{array}$ & $\begin{array}{c}10 \\
\text { Favours Placebo }\end{array}$ & 100 \\
\hline
\end{tabular}

Figure 2: Result of meta-analysis in sodium-glucose cotransporter-2 inhibitor in cardiovascular breakdown with decreased discharge division inside Dapagliflozin and Prevention of Adverse Outcomes in heart failure and EMPEROR-Reduced preliminary, (a) composite of cardiovascular demise and hospitalization of cardiovascular breakdown, (b) all-cause mortality, (c) cardiovascular mortality and (d) hospitalization of cardiovascular breakdown

(0.9 $\pm 4.7 \%)$. Hemoconcentration is suspected due to the secondary effect of SGLT-2 inhibitor in volume withdrawal; this accounted for around half of cardiovascular advantage [3]

SGLT-2 inhibitor improves cardiac energy metabolism. HF progress is correlated with mitochondrial oxidative digestion and the heart becomes more reliant on glycolysis as a wellspring of energy [9]. Mitochondria glucose oxidation decrease in HF leads to decrease in energy production and heart starvation [10]. SGLT- 2 inhibitors can increase circulating ketone levels, which are then used by the liver for ketogenesis [11], [12]. Ketone levels have been proposed to work on heart vivacious and cardiovascular proficiency [12], [13]. $\mathrm{HF}$ is an energy-starved condition, due to increase of mitochondrial oxidative metabolism [9]. Increasing ketone levels in blood due to SGLT-2 inhibitor can increment cardiovascular ketone oxidation rate and consequently further develop supply of energy to the heart [14]. Ketone implantation into patient with cardiovascular breakdown is likewise connected with progress of in contractile execution [15]. High level of ketone may increase the risk of renal failure. CREDENCE trial was performed who stated that usage of SGLT-2 inhibitor in type 2 diabetes mellitus and nephropathy significantly reduces risk of end-stage renal disease $(\mathrm{HR}=0.68$ [0.54-0.86], $p=0.002)$ and doubling of creatinine serum $(\mathrm{HR}=0.60$ [0.48-0.76] $p<0.001$ ) within 2.62-years of drug therapy [16].

SGLT-2 inhibitor also plays a strategic role in reducing inflammation. Inflammation is one of the many contributors to the severity of HF and pro-inflammatory biomarkers are raised in tolerance with cardiovascular breakdown and associate with the seriousness of the illness [17], [18]. SGLT-2 inhibitor has been shown to diminish the inflammatory process in patients with type 2 diabetes mellitus [19], [20]. SGLT-2 inhibitors also suppressing collagen synthesis in diabetic rat heart [21]. SGLT-2 inhibitor also played an important role in reducing ischemia/reperfusion injury. An in vivo study stated that there was significant reduction of ischemic in both diabetic (55 $\pm 0.7 \%-27 \pm 3 \%$, p $=0.001)$ and non-diabetic rat $(37 \pm 3 \%-20 \pm 2 \%, p=$ 0.001 ) [22]. SGLT-2 inhibitor reduces the role of $\mathrm{Na}^{+} /$ $\mathrm{H}^{+}$exchanger which can lower myocardial intracellular $\mathrm{Na}^{+}$levels. In vivo study stated that empaglifozin significantly reduces both intracellular $\mathrm{Na}^{+}(p<0.005)$ and intracellular $\mathrm{Ca}^{+}(p<0.005)$ in rat and rabbit heart. 
Hyperuricemia is a risk factor of HF [23]. SGLT-2 inhibitor can slightly decrease uric acid level in urine. This result might be ascribed to expanding of glycosuria in proximal tubules because of SGLT-2 inhibitor which can animate discharge of uric acid in urine [24].

REFORM trial is a placebo-controlled prospective cohort trial to evaluate left ventricular remodeling of dapagliflozin in type 2 diabetes mellitus for 12 months. Evaluation is performed using cardiac Magnetic resonance imaging (MRI) and echocardiography. Trial stated no significant change in left ventricular end-systolic volume $(p=0.594)$, left ventricular end-diastolic volume $(p=0.495)$, and left ventricular launch division $(p=0.732)$. However, there is significant increase of hematocrit $(p=0.005)$ and hemoglobin ( $p=0.002)$ level, also reduction of diastolic blood pressure $(p=0.001)$ and use of loop diuretic drug $(p<0.001)$ [25]. DAPA-left ventricular hypertrophy $(\mathrm{LVH})$ trial is a fake treatment controlled clinical preliminary to assess job of dapaglifozins in LVH with type 2 diabetes mellitus. Evaluation is also performed using cardiac $\mathrm{MRI}$, one of many examinations for measurement of cardiac mass. Trial stated no significant reduction of left ventricular mass $(p=0.383)$ [26].

Our meta-analysis provides solid evidence that empagliflozin or dapagliflozin assumes a significant part in decreasing cardiovascular breakdown hospitalizations in patients with HFrEF, and that these medications likewise lessen all-cause and cardiovascular mortality. Our meta-analysis confirms this important role.

\section{Conclusion}

Our finding in this meta-analysis shows a significant reduction both in primary and secondary outcome. There is a significant $22 \%$ decrease of composite of cardiovascular mortality and hospitalization of cardiovascular breakdown, $12 \%$ significant reduction of all-cause mortality, $13 \%$ significant reduction of cardiovascular mortality and $28 \%$ significant reduction of hospitalization of HF.

\section{Acknowledgment}

We are grateful to Dr Firman Suryadi Rahman (University of Airlangga) for taking the time to assist us with solutions and feedback on the manuscript. We also appreciate the enlightening discussions with Atiyatum Billah (University of Hang Tuah), Assya Amrilia Permata Putri (University of Hang Tuah), and Aufa (University of Hang Tuah). The Faculty of Medicine at Hang Tuah University funded this research.

\section{References}

1. Neal B, Perkovic V, Mahaffey KW, De Zeeuw D, Fulcher G Erondu $\mathrm{N}$, et al. Canagliflozin and cardiovascular and renal events in Type 2 diabetes. N Engl J Med. 2017;377(7):644-57. https://doi.org/10.1056/NEJMoa1611925 PMid:28605608

2. Kato ET, Silverman MG, Mosenzon O, Zelniker TA, Cahn A, Furtado $\mathrm{RH}$, et al. Effect of dapagliflozin on heart failure and mortality in Type 2 diabetes mellitus. Circulation. 2019;139(22):2528-36. https://doi.org/10.1161/ CIRCULATIONAHA. 119.040130

PMid:30882238

3. Zinman B, Wanner C, Lachin JM, Fitchett D, Bluhmki E, Hantel S, et al. Empagliflozin, cardiovascular outcomes, and mortality in Type 2 diabetes. N Engl J Med. 2015;373(22):2117-28. https:// doi.org/10.1056/NEJMoa1504720

PMid:26378978

4. McMurray JJ, Solomon SD, Inzucchi SE, Køber L, Kosiborod MN Martinez FA, et al. Dapagliflozin in patients with heart failure and reduced ejection fraction. NEngl J Med. 2019;381(21):1995-2008. https://doi.org/10.1056/NEJMoa1911303

PMid:31535829

5. Packer M, Anker SD, Butler J, Filippatos G, Pocock SJ, Carson P et al. Cardiovascular and renal outcomes with empagliflozin in heart failure. Ne Engl J Med. 2020;383(15):1413-24. https://doi. org/10.1056/NEJMoa2022190.

\section{PMid:32865377}

6. Mazidi M, Rezaie P, Gao HK, Kengne AP. Effect of sodiumglucose cotransport-2 inhibitors on blood pressure in people with Type 2 diabetes mellitus: A systematic review and metaanalysis of 43 randomized control trials with 22528 patients. J Am Heart Assoc. 2017;6(6):e004007. https://doi.org/10.1161/ JAHA. 116.004007

PMid:28546454

7. Ferrannini E, Mark M, Mayoux E. CV protection in the EMPAREG OUTCOME trial: A "thrifty substrate" hypothesis. Diabetes Care. 2016;39(7):1108-14. https://doi.org/10.2337/dc16-0330 PMid:27289126

8. Weber MA, Mansfield TA, Cain VA, lqbal N, Parikh S Ptaszynska A. Blood pressure and glycaemic effects of dapagliflozin versus placebo in patients with type 2 diabetes on combination antihypertensive therapy: $\mathrm{A}$ randomised, double-blind, placebo-controlled, phase 3 study. Lancet Diabetes Endocrinol. 2016;4(3):211-20. https://doi.org/10.1016/ S2213-8587(15)00417-9

PMid:26620248

9. Lopaschuk GD, Ussher JR, Folmes CD, Jaswal JS, Stanley WC Myocardial fatty acid metabolism in health and disease. Physiol Rev. 2010;90(1):207-58. https://doi.org/10.1152/ physrev.00015.2009

PMid:20086077

10. Wang W, Zhang L, Battiprolu PK, Fukushima A, Nguyen K, Milner $\mathrm{K}$, et al. Malonyl CoA decarboxylase inhibition improves cardiac function post-myocardial infarction. JACC Basic Transl Sci. 2019;4(3):385-400. https://doi.org/10.1016/j. jacbts.2019.02.003

PMid:31312761

11. Al Jobori H, Daniele G, Adams J, Cersosimo E, Triplitt C, DeFronzo RA, et al. Determinants of the increase in ketone concentration during SGLT2 inhibition in NGT, IFG and T2DM patients. Diabetes Obes Metab. 2017;19(6):809-13. https://doi. org/10.1111/dom.12881

PMid:28128510 
12. Ferrannini E, Baldi $S$, Frascerra $S$, Astiarraga B, Barsotti $E$, Clerico A, Muscelli E. Renal handling of ketones in response to sodium-glucose cotransporter 2 inhibition in patients with Type 2 diabetes. Diabetes Care. 2017;40(6):771-6. https://doi. org/10.2337/dc16-2724

PMid:28325783

13. Mudaliar S, Alloju S, Henry RR. Can a shift in fuel energetics explain the beneficial cardiorenal outcomes in the EMPA-REG OUTCOME study? A unifying hypothesis. Diabetes Care. 2016;39(7):1115-22. https://doi.org/10.2337/dc16-0542 PMid:27289124

14. Verma S, Rawat S, Ho KL, Wagg CS, Zhang L, Teoh H, et al. Empagliflozin increases cardiac energy production in diabetes: Novel translational insights into the heart failure benefits of SGLT2 inhibitors. JACC Basic TransI Sci. 2018;3(5):575-87. https://doi.org/10.1016/j.jacbts.2018.07.006 PMid:30456329

15. Nielsen R, Møller N, Gormsen LC, Tolbod LP, Hansson NH, Sorensen J, et al. Cardiovascular effects of treatment with the ketone body 3-hydroxybutyrate in chronic heart failure patients. Circulation. 2019;139(18):2129-41. https://doi.org/10.1161/ CIRCULATIONAHA.118.036459 PMid:30884964

16. Perkovic $\mathrm{V}$, Jardine $\mathrm{MJ}$, Neal $B$, Bompoint $S$, Heerspink $H J$, Charytan DM, et al. Canagliflozin and renal outcomes in Type 2 diabetes and nephropathy. N Engl J Med. 2019;380(24):2295-306. https://doi.org/10.1056/NEJMoa1811744 PMid:30990260

17. Dick SA, Epelman S. Chronic heart failure and inflammation: What do we really know? Circ Res. 2016;119(1):159-76. https:// doi.org/10.1161/CIRCRESAHA.116.308030 PMid:27340274

18. Fu M. Inflammation in chronic heart failure: What is familiar, what is unfamiliar? Eur J Heart Fail. 2009;11(2):111-2. https:// doi.org/10.1093/eurjhf/hfn039

PMid:19168507

19. Heerspink HJ, Perco P, Mulder S, Leierer J, Hansen MK, Heinzel $\mathrm{A}$, et al. Canagliflozin reduces inflammation and fibrosis biomarkers: A potential mechanism of action for beneficial effects of SGLT2 inhibitors in diabetic kidney disease. Diabetologia. 2019;62(7):1154-66. https://doi.org/10.1007/ s00125-019-4859-4

PMid:31001673
20. Iannantuoni $F$, de Marañon AM, Diaz-Morales $N$, Falcon $R$, Bañuls C, Abad-Jimenez Z, et al. The SGLT2 inhibitor empagliflozin ameliorates the inflammatory profile in Type 2 diabetic patients and promotes an antioxidant response in leukocytes. J Clin Med. 2019;8(11):1814. https://doi. org/10.3390/jcm8111814

PMid:31683785

21. Lee TM, Chang NC, Lin SZ. Dapagliflozin, a selective SGLT2 Inhibitor, attenuated cardiac fibrosis by regulating the macrophage polarization via STAT3 signaling in infarcted rat hearts. Free Radic Biol Med. 2017;104:298-310. https://doi. org/10.1016/j.freeradbiomed.2017.01.035

PMid:28132924

22. Lim VG, Bell RM, Arjun S, Kolatsi-Joannou M, Long DA Yellon DM. SGLT2 inhibitor, canagliflozin, attenuates myocardial infarction in the diabetic and nondiabetic heart. JACC Basic TransI Sci. 2019;4(1):15-26. https://doi.org/10.1016/j. jacbts.2018.10.002

PMid:30847415

23. Baartscheer A, Schumacher CA, Wüst RC, Fiolet JW, Stienen GJ, Coronel R, et al. Empagliflozin decreases myocardial cytoplasmic $\mathrm{Na}+$ through inhibition of the cardiac $\mathrm{Na}+/ \mathrm{H}+$ exchanger in rats and rabbits. Diabetologia. 2017;60(3):568-73. https://doi.org/10.1007/s00125-016-4134-x PMid:27752710

24. Chino Y, Samukawa Y, Sakai S, Nakai Y, Yamaguchi JI, Nakanishi T, et al. SGLT2 inhibitor lowers serum uric acid through alteration of uric acid transport activity in renal tubule by increased glycosuria. Biopharm Drug Dispos. 2014;35(7):391-404.

PMid:25044127

25. Singh JS, Mordi IR, Vickneson K, Fathi A, Donnan PT, Mohan M, et al. Dapagliflozin versus placebo on left ventricular remodeling in patients with diabetes and heart failure: The REFORM trial. Diabetes Care. 2020;43(6):1356-9. https://doi.org/10.2337/ dc19-2187

PMid:32245746

26. Brown AJ, Gandy S, McCrimmon R, Houston JG, Struthers AD, Lang CC. A randomized controlled trial of dapagliflozin on left ventricular hypertrophy in people with type two diabetes: The DAPA-LVH trial. Eur Heart J. 2020;41(36):3421-32. https://doi. org/10.1093/eurheartj/ehaa419

PMid:32578850 